study because the data were not sufficient to calculate chloride balance.

Though five patients suffering from subacute bacterial endocarditis were rendered hypokalaemic by 100 mega units of sodium penicillin $G$ daily, there was one patient with coxitis who did not develop any electrolyte disturbance. This suggests that additional factors, such as a tendency to sodium retention (Schwartz et al., 1955) with mild secondary aldosteronism due to clinically apparent or inapparent heart failure or inadequate food intake, form the necessary background for penicillin to cause potassium depletion.

Since patients with subacute bacterial endocarditis often present with heart failure and receive digitalis, it is mandatory to prevent potassium depletion as well as sodium loads. This is easily achieved by substituting the potassium salt of penicillin for the sodium salt. Unfortunately it is more and more difficult to get potassium penicillin $G$ for medical use. The reason for this is probably a largely unjustified fear of inducing potassium intoxication in patients with renal failure. The only instance of fatal potassium intoxication which we were able to find reported in the literature occurred immediately after an obviously too "rapid intravenous administration" of 20 mega units of potassium penicillin $G$ (Thomson, 1964). In the event of renal failure "massive" therapy with potassium penicillin $G$ must be reduced in order to avoid both the central nervous system toxicity of high serum levels of penicillin and the hyperkalaemia. If potassium penicillin $G$ is not available, potassium depletion and sodium overload may be prevented by combining sodium penicillin with potassium-sparing diuretics like aldactone, triamterene, or amiloride. These drugs block the exchange of sodium for potassium in the distal tubule (Baer et al., 1966 ; Liddle, 1966). Consequently the non-reabsorbable anion penicillin is forced to appear in the urine together with the cation sodium and cannot cause or aggravate either congestive heart failure or hypokalaemia.

\section{REFERENCES}

Baer, J. E., Mucha, C. M., Spitzer, S. A., and Yee, H. W. (1966). Fed. Proc., 25, 197.

Black, D. A. K., and Milne, M. D. (1952). Clin. Sci., 11, 397.

Blahd, W. H. and Bassett, S. H. (1953). Metabolism, 2, 218

Bloomer, H. A., Barton, L. J., and Maddock, R. K., jun. (1967). 7. Amer. med. Ass., 200, 121 .

Clapp, J. R., Rector, F. C., jun., and Seldin, D. W. (1962). Amer. F. Physiol., 202, 781 .

Eagle, H., and Newman, E. (1947). F. clin. Invest., 26, 903.

Gardner, L. I., MacLachlan, E. A., and Berman, H. (1952). f. gen. Physiol., 36, 153.

Gulyassy, P. F., van Ypersele de Strihou, C., and Schwartz, W. B. (1962). 7. clin. Invest., 41, 1850.

Liddle, G. W. (1966). Ann. N.Y. Acad. Sci., 139, 466

Malnic, G., Klose, R. M., and Giebisch, G. (1966). Amer. 7. Physiol. $211,529$.

Rector, F. C., jun., Bloomer, H. A., and Seldin, D. W. (1964). F. clin. Invest., 43, 1976.

Schwartz, W. B., Jenson, R. L., and Relman, A. S. (1955). F. clin. Invest., 34, 673 .

Seldin, D. W., Rector, F., Carter, N., and Copenhaver, J. (1954). Amer. 7. Med., 16, 608 .

Seldin, D. W., Welt, L. G., and Cort, J. H. (1956). Yale 7. Biol. Med.,

29, 229.
Smith, H., Lerner, P. I., and Weinstein, L. (1967). Arch. intern. Med., $120,47$.

Squires, R. D., and Huth, E. J. (1959). F. clin. Invest., 38, 1134

Thomson, R. L. (1964). New Engl. F. Med., 271, 1218.

Weinstein, L., Lerner, P. I., and Chew, W. H. (1964). New Engl. f. Med., 271, 525 .

\title{
Plasma Levels of Immunoreactive Corticotrophin in Patients with Cushing's Syndrome
}

\author{
G. M. BESSER,* M.D., B.SC., M.R.C.P. ; J. LANDON, $†$ M.D.
}

\begin{abstract}
Summary : Plasma levels of immunoreactive corticotro$S$ phin (A.C.T.H.) have been determined in 56 patients with Cushing's syndrome by means of a homologous radioimmunoassay. In untreated Cushing's disease (bilateral adrenal hyperplasia due to excessive A.C.T.H. secretion from the pituitary) plasma values ranged from 40 to $200 \mu \mu \mathrm{g} . / \mathrm{ml}$., between 8 and 10 a.m., compared with a range in normal subjects of 12 to $60 \mu \mu \mathrm{g} . / \mathrm{ml}$. Considerably raised levels, often above $2,000 \mu \mu \mathrm{g} . / \mathrm{ml}$., were found in patients with Cushing's disease after bilateral adrenalectomy. A.C.T.H. concentrations were usually higher in patients with bilateral adrenal hyperplasia associated with ectopic A.C.T.H. production than in patients with untreated Cushing's disease; whereas plasma A.C.T.H. was undetectable in the presence of an adrenocortical tumour. All patients with Cushing's syndrome failed to show the normal circadian rhythm of circulating A.C.T.H. levels.
\end{abstract}

* Lecturer to the Medical Professorial Unit. † Professor of Chemical Pathology.

St. Bartholomew's Hospital, London E.C.1.

\section{Introduction}

Cushing's syndrome, unless due to corticosteroid therapy, is the result of increased cortisol secretion from either an adrenocortical tumour or bilateral adrenocortical hyperplasia. On the basis of bioassay data it appears that circulating A.C.T.H. is undetectable in the plasma of patients with Cushing's syndrome associated with an adrenal adenoma or carcinoma, whereas patients with bilateral adrenal hyperplasia have high normal or raised values (Clayton, 1958; Williams et al., 1961 ; Vance et al., 1962 ; Ney et al., 1963 ; Davies, 1964 ; Nelson and Sprunt, 1965 ; Retiene et al., 1965 ; Nelson et al., 1966). The determination of plasma A.C.T.H. levels is therefore of value in differentiating between the various causes of Cushing's syndrome.

Despite their specificity, bioassays for A.C.T.H. are technically complex and time-consuming and require large volumes of blood to obtain accurate results. The recent introduction of radioimmunoassays for this hormone (Yalow et al., 1964; Demura et al., 1966 ; Landon and Greenwood, 1968 ; Orth et al., 1968) enables circulating levels to be determined more simply by using between 1 and $10 \mathrm{ml}$. of plasma. Large numbers of subjects can be studied, with serial determinations 
in individual patients. It should be noted, however, that whereas bioassay determines only biologically active A.C.T.H., immunoassay may also be influenced by biologically inactive fragments (Imura et al., 1965 ; Fleischer et al., 1966 ; Landon et al., 1968). Thus it is necessary to ensure that the results obtained by the two techniques are similar before reliance can be placed on radioimmunological assays in clinical practice.

The present paper summarizes the results obtained in a group of patients with treated or untreated Cushing's syndrome by use of a homologous radioimmunoassay for the determination of plasma levels of immunoreactive human A.C.T.H., and compares the results obtained with published data.

\section{Patients and Methods}

In all, 56 patients with Cushing's syndrome were studied. There were 20 with untreated Cushing's disease (bilateral adrenal hyperplasia dependent on secretion of A.C.T.H. by the anterior pituitary), one of whom had radiological evidence of an enlarged pituitary fossa ; 16 with Cushing's disease treated by total bilateral adrenalectomy, of whom five had an expanded pituitary fossa; 15 with bilateral adrenal hyperplasia due to an ectopic source of A.C.T.H. (11 with a bronchial, 2 with a pancreatic, 1 with a gastric, and 1 with a colonic carcinoma); 4 with an adrenal adenoma; and 1 with an adrenal carcinoma.

Plasma levels of immunoreactive A.C.T.H. were determined as reported previously (Landon and Greenwood, 1968), and plasma corticosteroid values (as 11-hydroxycorticoids) were determined by a fluorimetric procedure (Mattingly, 1962).

\section{Results}

Basal plasma levels of immunoreactive A.C.T.H. between 8 and 10 a.m. are shown in Fig. 1. In the majority of patients with untreated Cushing's disease values lay in or slightly

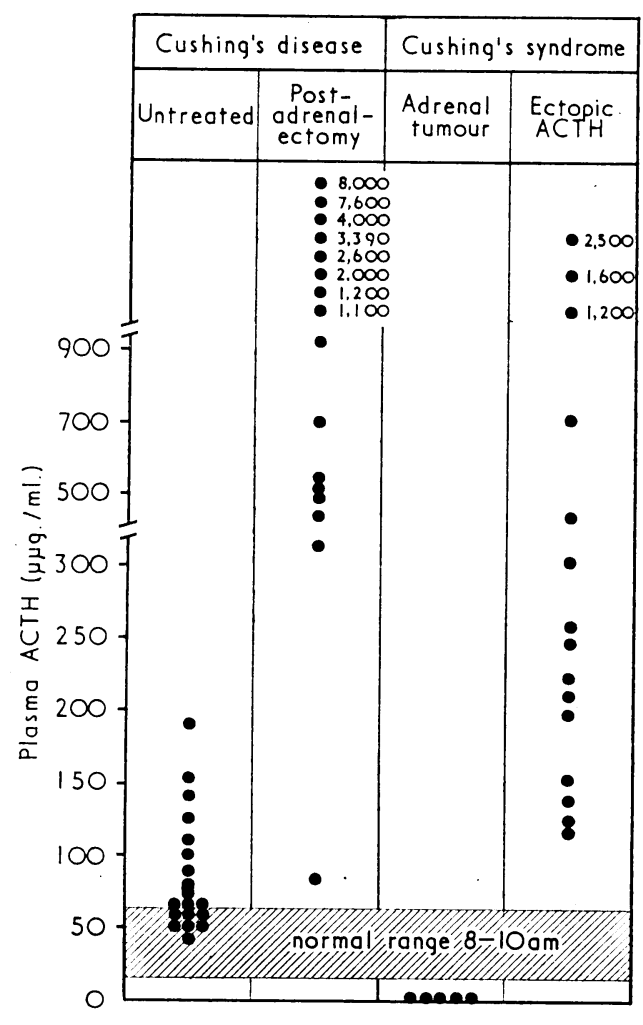

FIG. 1.-Plasma concentration of immunoreactive A.C.T.H. in 56 patients with Cushing's syndrome. The normal morning range (8 to 10 a.m.) is shown by the shaded area.

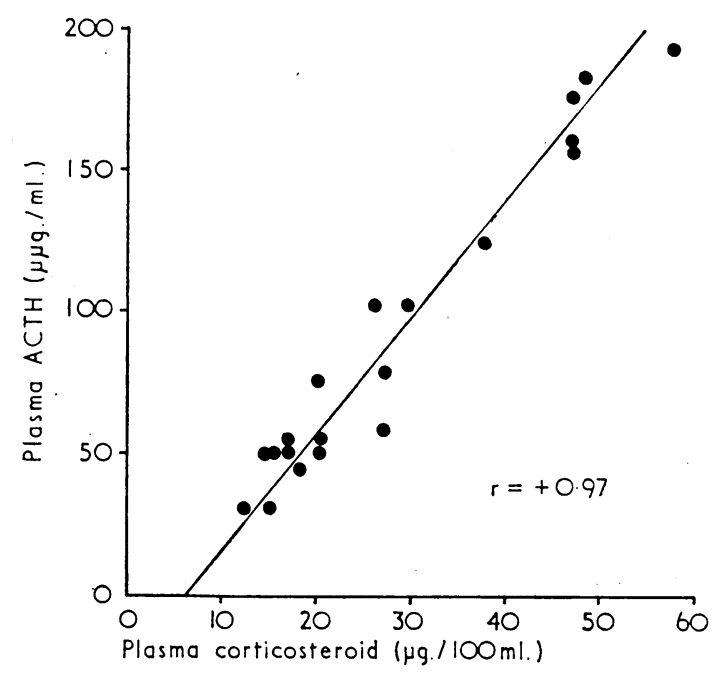

FIG. 2.-Correlation between plasma A.C.T.H. and corticosteroid concentrations determined in the same blood samples in 11 patients with untreated Cushing's disease. Some patients were studied on more than one occasion.

above the upper range found in 50 normal subjects (12 to 60 $\mu \mu \mathrm{g} . / \mathrm{ml}$.) and only 6 of the 20 had basal plasma levels of more than $100 \mu \mu \mathrm{g} . / \mathrm{ml}$. Basal values were markedly raised in patients whose Cushing's disease had been treated by total bilateral adrenalectomy, with the exception of one with a level of only $75 \mu \mu \mathrm{g} . / \mathrm{ml}$. (but this plasma had been stored, deep frozen, for more than two years before assay). The five post-adrenalectomy patients with radiological evidence of a pituitary tumour had levels over $900 \mu \mu \mathrm{g}$. $/ \mathrm{ml}$. All five patients with adrenal tumours had undetectable plasma levels of immunoreactive A.C.T.H. (less than $10 \mu \mu \mathrm{g} . / \mathrm{ml}$.), whereas the 15 patients with Cushing's syndrome associated with a nonadrenal carcinoma had raised levels usually in excess of 200 $\mu \mu \mathrm{g} . / \mathrm{ml}$. In the patients with bilateral adrenal hyperplasia A.C.T.H. levels appeared to vary with the severity of the disease, and in untreated Cushing's disease correlated closely with the plasma corticosteroid values (Fig. 2). Deviation from this correlation occurred in those patients with an ectopic site of A.C.T.H. production who had very high plasma A.C.T.H. concentrations in excess of those necessary to induce a maximum adrenocortical response.

A characteristic feature of all patients with Cushing's syndrome was the absence of a circadian rhythm of plasma A.C.T.H. (see Fig. 3). Thus the values found at midnight and midday were similar to the basal morning levels, whereas in a small group of five control subjects the midnight levels had fallen to $10 \mu \mu \mathrm{g} . / \mathrm{ml}$. or less.

\section{Discussion}

In patients with untreated Cushing's disease basal morning A.C.T.H. levels lie within or slightly above the upper normal range, but after total bilateral adrenalectomy much higher levels are found, often in excess of $2,000 \mu \mu \mathrm{g} . / \mathrm{ml}$. Our findings support the postulate of Nelson and Sprunt (1965) and Nelson et al. (1966) that Cushing's disease can be subdivided into stages based on plasma A.C.T.H. levels. Stage 1 is represented by those patients in whom morning A.C.T.H. values lie within or only slightly above the normal range and whose increased cortisol secretion rates are due to the maintenance of such A.C.T.H. levels throughout 24 hours (Ney et al., 1963 ; Retiene et al., 1965). In stage 2 the plasma A.C.T.H. values are more markedly raised and this is reflected by the greater severity of the disease. In stage 3 , most commonly seen after bilateral adrenalectomy, circulating A.C.T.H. levels are extremely high. Such patients are often pigmented and it is in 
this group that radiological or other evidence of a pituitary tumour is most common.

Patients with an adrenal tumour have undetectable plasma levels of A.C.T.H., whereas those with bilateral adrenal hyperplasia due to an ectopic source of A.C.T.H. have raised values often in excess of $200 \mu \mu \mathrm{g} . / \mathrm{ml}$. This latter finding is consistent with the markedly raised cortisol secretion rates and plasma and urinary corticosteroid levels which characterize this condition, and with the clinical observation that many of these patients become pigmented (Liddle et al., 1965).

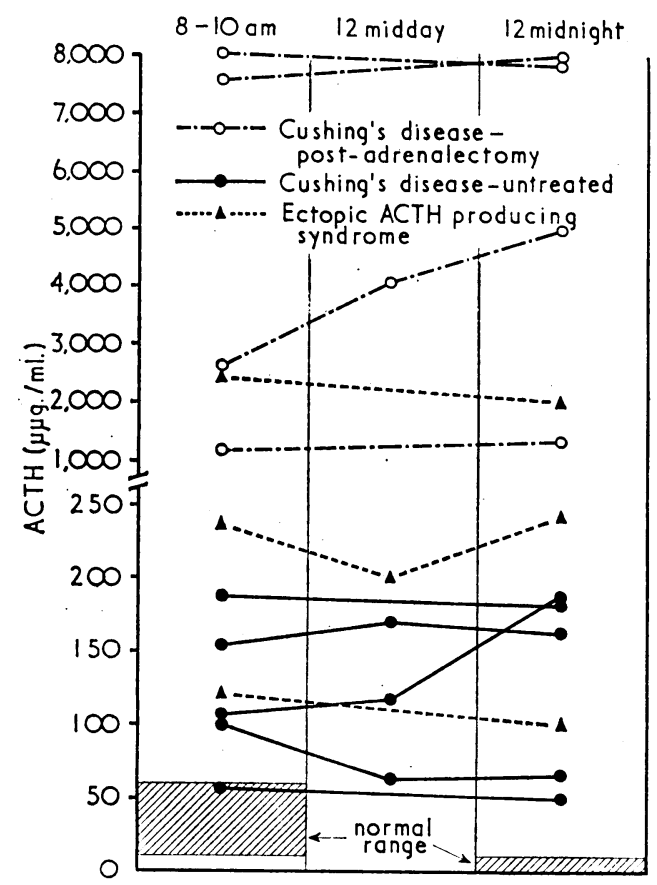

Fig. 3.-Plasma A.C.T.H. concentration at different times throughout the day in 12 patients with Cushing's syndrome of various aetiologies. The absent circadian rhythm is shown. The shaded areas represent the normal ranges.

From a study of the references given in the introduction it is apparent that there is close agreement between the results of plasma A.C.T.H. determinations previously reported in Cushing's syndrome using bioassay and the accumulating results of radioimmunoassay procedures. Thus it seems justified to use immunological assays for the clinical investigation of Cushing's syndrome. It is of interest, therefore, to consider the practical value of plasma A.C.T.H. determinations in the investigation of such patients. When combined with the determination of plasma corticosteroid levels they help to distinguish between the possible causes of the syndrome. Thus the absence of circulating A.C.T.H., together with raised plasma corticosteroid levels, indicates the presence of an adrenal carcinoma or adenoma and excludes bilateral adrenal hyperplasia due either to a pituitary or to an ectopic source of A.C.T.H. This was well demonstrated by two patients who presented with severe Cushing's syndrome and markedly raised plasma and urinary corticosteroid levels, which failed to suppress during the administration of large doses of dexamethasone. Raised plasma A.C.T.H. levels confirmed the presence of adrenal hyperplasia. Without this information it would have been difficult to exclude an adrenal tumour other than by laparotomy. The assay has also proved useful in patients in whom the administration of spironolactone precluded plasma corticosteroid assays by fluorimetric procedures.

Though of undoubted value in establishing the differential diagnosis in a moderate or severe case of Cushing's syndrome, the ability to determine plasma levels of A.C.T.H. would appear to offer no advantage as compared with plasma or urinary corticosteroid assays in the establishment of the diagnosis of early Cushing's disease. Our findings and those of Ney et al. (1963), that there is a close correlation between both plasma and urinary corticosteroid levels and circulating A.C.T.H. values in patients with pituitary-dependent adrenal hyperplasia, suggest that, provided adrenal function is normal, each corticosteroid determination can be looked on as a bioassay for A.C.T.H. Consequently it is now our custom to restrict the number of A.C.T.H. assays on each patient suspected of having Cushing's syndrome to two morning samples. These levels will help to differentiate between A.C.T.H.dependent adrenocortical hyperplasia and an autonomous tumour. Establishment of the diagnosis of the syndrome itself, however, is based on circadian rhythm studies and standard procedures such as the insulin hypoglycaemia and dexamethasone suppression tests (James et al., 1968) which use urinary and/or plasma corticosteroid determinations, since these are easier and more accurate than A.C.T.H. assays.

We gratefully acknowledge the co-operation of the large number of clinicians who have sent us plasma samples, and especially the continued interest of Professor E. F. Scowen and Professor F. C. Greenwood. We also thank Miss C. Bellamy, Mrs. M. Marie, and Mrs. J. Heath for skilled technical assistance.

Requests for reprints should be addressed to Professor J. Landon.

\section{REFERENCES}

Clayton, B. E. (1958). Proc. roy. Soc. Med., 51, 558.

Davies, B. M. A. (1964). Acta endocr. (Kbh.), 45, 55.

Demura, H., West, C. D., Nugent, C. A., Nakagawa, K., and Tyler, F. H. (1966). F. clin. Endocr., 26, 1297.

Fleischer, N., Givens, J. R., Abe, K., Nicholson, W. E., and Liddle, G. W. (1966). Endocrinology, 78, 1067.

Imura, H., Sparks, L. L., Grodsky, G. M., and Forsham, P. H. (1965). 7. clin. Endocr., 25, 1361.

James, V. H. T., Landon, J., Wynn, V., and Greenwood, F. C. (1968), 7. Endocr., 40, 15 .

Landon, J., Girard, J., and Greenwood, F. C. (1968). In Protein and Polypeptide Hormones, Excerpta Medica International Congress Series, No. 161, part 1, p. 29. Amsterdam.

Landon, J., and Greenwood, F. C. (1968). Lancet, 1, 273.

Liddle, G. W., Givens, J. R., Nicholson, W. E., and Island, D. P. (1965). Cancer Res., 25, 1057

Mattingly, D. (1962). F. clin. Path., 15, 374.

Nelson, D. H., and Sprunt, J. G.'(1965). In Proceedings of 2nd International Congress on Endocrinology, Excerpta Medica International Congress Series, No. 83, part 2, p. 1053. Amsterdam.

Nelson, D. H., Sprunt, J. G., and Mims, R. B. (1966). F. clin. Endocr., 26, 722 .

Ney, R. L., Shimizu, N., Nicholson, W. E., Island, D. P., and Liddle, G. W. (1963). F. clin. Invest., 42, 1669.

Orth, D. N., Island, D. P., Nicholson, W. E., Abe, K., and Woodham, J. P. (1968). In Radioisotopes in Medicine, No. 11. In press.

Retiene, K., Espinoza, A., Marx, K. H., and Pfeiffer, E. F. (1965). Klin. Wschr., 43, 205.

Vance, V. K., Reddy, W. J., Nelson, D. H., and Thorn, G. W. (1962). 7. clin. Invest., $41,20$.

Williams, W. C., Island, D. P., Oldfield, R. A. A., and Liddle, G. W. (1961). F. clin. Endocr., 2i, 426.

Yalow, R. S., Glick, S. M., Roth, J., and Berson, S. A. (1964). f. clin. Endocr., 24, 1219. 